\title{
Developing A Mobile Web for Innovative University Assessment System: Thailand Talent Mobility Programme
}

\author{
https://doi.org/10.3991/ijim.v13i11.10924 \\ Kritika Kongsoontornkijkul, Rath Pichyangkura ${ }^{(凶)}$, \\ Pakpachong Vadhanasindhu, and Kanlaya Vanichbuncha \\ Chulalongkorn University, Bangkok, Thailand \\ prath@chula.ac.th
}

\begin{abstract}
Empirical research methods were used to study the Thailand Talent Mobility Programme and critical factors effecting participation in the project; from the perspectives of academic researchers in Science, Technology, and Innovation, in order to strengthen the competitiveness of technological innovation in Thailand. On the basis of questionnaire surveys of 58 universities and 17 research institutes, 613 academic researchers across the country responded the survey. All responses were analyzed through factor analysis and regression analysis methods. We conducted a thorough study of the impact of all factors to successful programme participation. This research study also identifies recommendations and solutions for successful personnel sharing models in Thailand. A mobile web for innovative university assessment system is also introduced as a supporting tool.
\end{abstract}

Keywords - University-Industry Linkage (UIL); Knowledge Management (KM); University-Industry Collaboration (UIC); Talent Mobility (TM); National Research University (NRU); Personnel Sharing Model, University Assessment System, Mobile Web

\section{Introduction}

University-Industry Linkage (UIL) has become crucial in the research arena for economic competitiveness [1]. Knowledge Management allows organization to exploit its human intellectual asset to improve competitive advantage [2]. Researchers in Science, Technology, and Innovation are therefore increasingly in high demand and personnel sharing mechanism has also been emerged as a strategic national policy in the establishment of national innovation system globally. Among the different types of personnel sharing models, University-Industry Collaboration (UIC) happens to be an important mechanism in many countries. Talent Mobility (TM) is a growing practice at many universities/institutions and this model works well in the US and Europe. It has become a subject of great interest to academics, industry leaders and policymakers, as it is now acknowledged that this model is valuable for innovation and very 
important for researchers, especially when the area of knowledge has an applied component; science, technology, innovation [3].

Our objective is to shed some light on the factors or criteria of participation in a university-industry collaboration carried out through projects organised as TM.

To achieve our purpose, we accomplished an empirical study based on the analysis of questionnaire surveys of 58 universities (9 NRUs and 49 non-NRUs) and 17 research institutes which 613 academic researchers across the country responded the survey sharing their collaboration perspectives on Thailand Talent Mobility Programme of The National Science Technology and Innovation Policy Office (STI).

In this point, there are some considerations that should be made to clarify the approach of this contribution. First, the study gave insights into the scholars' point of view on factors affecting their decision making to participate in the TM project, gathered by selected nationwide academic researchers in Science, Technology, and Innovation. Second, it has been to identify personnel sharing models practiced in Thailand. Finally, the chosen sample of academic researchers provided us with their requirements on tool or application for innovative university assessment system in sharing experts in science, technology and innovation between universities and industries.

\section{Literature Review and Theoretical Framework}

\subsection{Literature review}

Knowledge transfer challenges in the emerging country context: Knowledge transfer enhances growth opportunities for emerging markets [4] [5] [6]. Large-scale knowledge transfer collaborations are often sponsored by the state as they require a high level of funding, significant resources and have a strategic economic importance to develop indigenous innovation capabilities [7]. A strategic role of such projects creates a high interest from potential stakeholders; government, university, and industry; and a long term economic growth can be achieved if the knowledge obtained is fully utilized and developed [8].

For developing countries and middle-income countries, therefore, it is essential to learn and apply practices and guidelines as developed countries around the world; such as the creation of a science park, Technopolis or technology city, Innopolis, which is a driving force for technological innovation; including the creation and promotion of manpower and researchers in the field of expertise from the government to work in the industry (Talent Mobility). This is considered to create the infrastructure needed for long-term competitive economic growth of the country [9].

University and Industry Linkage (UIL): Key factors in the innovation process involve interaction and collaboration among three players [10]: university, industry, and government [11]. Successful university-industry linkage (UIL) can be measured by efficiency, continuous marketing sales growth, understanding between university and corporate cultures, understanding of industrial problems, continuity of technology transfer to industry, and communication [1]. 
For Thailand, the Thai government has initiated the National Research University (NRU) project in 2009 under the direction of the Office of the Higher Education Commission (OHEC). The goal is to develop academic capacity to promote research activities in the country and to build links between universities and industries for Thailand's competitiveness [12]. Nine outstanding research universities were selected.

In general, there are six official forms of personnel sharing between universities and industries in Thailand: Consultancy and Reach-Out; Licensing; Contract Research; Collaborative Research; Talent Mobility; and Academic Entrepreneurship [13].

Models of Talent Mobility: World Economic Forum (WEF) defines Talent Mobility as "the physical mobility of talent within or across organizations and industries as well as the professional movement of workers across occupations or skill sets" [14]. TM is not a goal in itself but is often linked with sustainable economic growth objectives and can promote research and innovation as well as increase researchers' employability and career development.

The Talent Mobility Programme in Thailand by The National Science Technology and Innovation Policy Office (STI) has been officially launched since 2013 dividing into four phases. It currently conducts cooperation with 21 universities, 7 government agencies, 1 foundation, and 344 enterprises; with a total of 484 collaborative projects and 4 clearing house centers nationwide. At present, the programme consists of 766 professors/researchers, and 703 assistant researchers of which 87 Doctoral Degree, 170 Master's Degree, and 446 Bachelor's Degree. (Source: STI Report, 1 March 2019)

A Mobile Web for Innovative University Assessment System, therefore, is introduced to facilitate the programme participation for the university. It was developed on the basis of personnel sharing models derived from three major effecting factors; as described in the following theoretical framework displayed in Figure 1. To further accelerate processes in knowledge management, the use of mobile technologies can also be integrated within the framework [2].

\subsection{Theoretical framework}

The theoretical framework comprises of three major parts; effecting factors influencing academic researchers' decision making in the Talent Mobility Programme participation, personnel sharing models, and a mobile web for innovative university assessment system, as displayed in the above theoretical framework as Figure 1. 


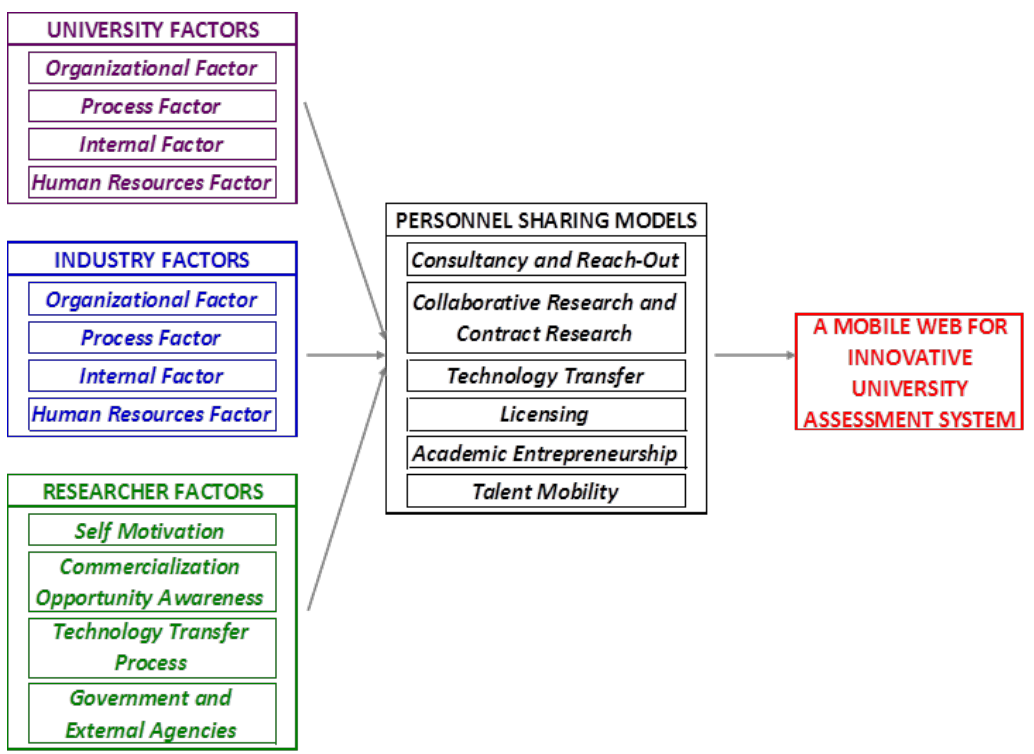

Fig. 1. Theoretical Framework

\section{$3 \quad$ Methodology}

\subsection{Sampling and data collection}

The survey followed a data collection technique and was performed from July to October 2018; both online and offline. Questionnaires were distributed to 21,526 scholars via direct email and were collected from 656 participants of researcher development courses organized nationwide by The National Research Council of Thailand. This study yielded 613 professors/researchers; expertise in the fields of Science, Technology, and Innovation, from National Research Universities, non-NRUs, and other governmental institutions; respectively.

\subsection{Questionnaire}

A questionnaire was used as the data collection instrument. It comprised six sections as demographic information, three major parts of factors effecting programme participation, models of personnel sharing, and acquisition of a mobile web for the university assessment system. All questionnaire items were adopted from existing studies. The questionnaire topics and questions had all undergone consultations with experts in the related fields to ensure clarity and suitability of the content and format. A five-point Likert scale was used to capture the responses; ranging from 1 Strongly Disagree, 2 Disagree, 3 Neutral, 4 Agree, and 5 Strongly Agree. All questions in the questionnaire were written in Thai language as this was the mother tongue of the participants. Pertinent demographic questions were also included in the survey. 


\subsection{Data analysis}

Data were analyzed using the Statistical Package for the Social Sciences (SPSS) version 22. Factors effecting Talent Mobility Programme participation were determined and a regression analysis then was used to ascertain the extent to which all factors contributed to the personnel sharing models. Participants' requirement to use a mobile web for the university assessment system was also determined.

\section{$4 \quad$ Results}

They were found that industry factors have an overall significant effect on academic researchers' participation decision on the Talent Mobility Programme; followed by university factors. The government, therefore, must strengthen guiding support for industries and policy support for universities/research institutes [15].

Summarising, 613 academic researchers provided us with a description that the sample group had the most expertise in science; 241 people, accounting for 39.4 percent and highest interested in food industry; 205 people, or 33.7 percent. The majority of respondents also decided to join the project; 415 people, representing 67.7 percent. Technology Transfer was considered the most significant model followed by Collaborative Research and Contract Research. For requirements on tool or application for university assessment system in personnel sharing mechanisms, most of the samples; 552 people, or 90.0 percent needed a supporting tool.

\subsection{Demographic information}

The sample consisted of 613 participants; males $(56.8 \%)$ and females (43.2\%). Most of them were aged between 40 and 49 years (38.7\%), followed by those aged between 30 and 39 years (38.3\%). In terms of education level, most respondents (63.8\%) were Doctoral Degree followed by Master's Degree (26.9\%). The majority of participants $(37.5 \%)$ were lecturers, followed by assistant professors $(25.3 \%)$. For year of service, most respondents have more than 16 years $(32.0 \%)$, followed by those worked between 6 and 10 years (26.8\%). Most researchers (76.0\%), were from National Research Universities while the rest (24.0\%) were non-NRUs'/other institutions' experts. The majority of participants $(39.4 \%)$ were expertise in science, followed by engineering and industry (13.7\%). In terms of type of interested industry, most respondents $(33.7 \%)$ were interested in food industry followed by medicine and dietary supplements $(27.3 \%)$ as summarized in Table 1.

Table 1. Demographic Information $(n=613)$

\begin{tabular}{|l|l|c|c|}
\hline \multicolumn{2}{|l|}{ Construct } & Number & Percent \\
\hline \multirow{2}{*}{ Gender } & Male & 348 & $56.80 \%$ \\
\cline { 2 - 4 } & Female & 265 & $43.20 \%$ \\
\hline \multirow{2}{*}{ Age } & $40-49$ & 237 & $38.70 \%$ \\
\cline { 2 - 4 } & $30-39$ & 235 & $38.30 \%$ \\
\hline Education Level & Doctoral Degree & 391 & $63.80 \%$ \\
\hline
\end{tabular}




\begin{tabular}{|c|c|c|c|}
\hline & Master's Degree & 165 & $26.90 \%$ \\
\hline \multirow{2}{*}{ Academic Position } & Lecturer & 230 & $37.50 \%$ \\
\hline & Assistant Professor & 155 & $25.30 \%$ \\
\hline \multirow{2}{*}{ Year of Service } & Over 16 & 196 & $32.00 \%$ \\
\hline & 06-Oct & 164 & $26.80 \%$ \\
\hline \multirow{2}{*}{ Type of University } & National Research University (NRU) & 466 & $76.00 \%$ \\
\hline & Non-NRU/Other Institutions & 147 & $24.00 \%$ \\
\hline \multirow{2}{*}{ Field of Expertise } & Science & 241 & $39.40 \%$ \\
\hline & Engineering and Industry & 84 & $13.70 \%$ \\
\hline \multirow{2}{*}{ Type of Interested Industry } & Food & 205 & $33.70 \%$ \\
\hline & Medicine and Dietary Supplements & 166 & $27.30 \%$ \\
\hline
\end{tabular}

\subsection{Factors effecting researcher's decision making in the talent mobility programme participation}

Descriptive analysis was conducted to study factors effecting respondent's decision making in the Talent Mobility Programme participation. Results of the analysis are shown in Table 2. Factor R-2 (Opportunity perception in bringing research into the market) was considered the most significant with the highest mean (mean=4.17), followed by Factor U-2 (Working process of the university), Factor I-1 (Organizational factors and Organization management of the industry), and Factor U-3 (Internal factors of the university) as the respondents described very important (mean=4.06) as revealed in Table 2.

Table 2. Factors Effecting Researcher's Decision Making in the TM Programme Participation

\begin{tabular}{|c|l|c|c|}
\hline & \multicolumn{1}{|c|}{ Items } & Mean & SD \\
\hline 1 & $\begin{array}{l}\text { University Factor 1 (U-1): Organizational factors and Organization management of the } \\
\text { university }\end{array}$ & 3.76 & 1.106 \\
\hline 2 & University Factor 2 (U-2): Working process of the university & 4.06 & 1.015 \\
\hline 3 & University Factor 3 (U-3): Internal factors of the university & 4.06 & 0.992 \\
\hline 4 & University Factor 4 (U-4): Human resource factors of the university & 3.81 & 1.037 \\
\hline 5 & $\begin{array}{l}\text { Industry Factor 1 (I-1): Organizational factors and Organization management of the } \\
\text { industry }\end{array}$ & 4.06 & 0.999 \\
\hline 6 & Industry Factor 2 (I-2): Working process of the industry & 3.98 & 0.977 \\
\hline 7 & Industry Factor 3 (I-3): Internal factors of the industry & 4.1 & 0.942 \\
\hline 8 & Industry Factor 4 (I-4): Human resource factors of the industry & 3.98 & 0.923 \\
\hline 9 & Researcher Factor 1 (R-1): Motivation of the researcher & 3.95 & 0.994 \\
\hline 10 & Researcher Factor 2 (R-2): Opportunity perception in bringing research into the market & 4.17 & 0.897 \\
\hline 11 & Researcher Factor 3 (R-3): Technology transfer process & 3.98 & 0.941 \\
\hline 12 & Researcher Factor 4 (R-4): Support from government and external agencies & 3.76 & 1.115 \\
\hline
\end{tabular}

\subsection{Researchers' decision on programme participation}

The result showed the number and percentage of the sample group regarding their decision making to participate in the Talent Mobility Programme. Most of the sample group decided to join the project; 415 people, accounting for 67.7 percent, followed 
by decided not to participate the programme; 198 people, representing 32.3 percent as indicated in Table 3.

Table 3. Researchers' Decision on Programme Participation

\begin{tabular}{|l|c|c|}
\hline \multicolumn{1}{|c|}{ Decision } & Number & Percent \\
\hline Decided to Participate & 415 & 67.7 \\
\hline Decided not to Participate & 198 & 32.3 \\
\hline Overall & 613 & 100 \\
\hline
\end{tabular}

\subsection{University-Industry personnel sharing models}

Analysis result of the personnel sharing models between university and industry is shown in Table 4. The sample group agreed that it was overall very important (mean=4.07). Technology Transfer was considered the most significant with the highest mean (mean=4.24), followed by Collaborative Research and Contract Research as the respondents described very important (mean=4.20). Talent Mobility, however, was rated very important as the fifth rank (mean=4.06) and Other Models were ranked with the lowest mean (mean=3.73) as presented in Table 4.

Table 4. University-Industry Personnel Sharing Models

\begin{tabular}{|c|l|c|c|}
\hline \multicolumn{1}{|c|}{ Items } & Mean & SD \\
\hline 1 & Technology Transfer & 4.24 & 0.826 \\
\hline 2 & Collaborative Research and Contract Research & 4.2 & 0.826 \\
\hline 3 & Consultancy and Reach-Out & 4.13 & 0.823 \\
\hline 4 & Licensing & 4.1 & 0.878 \\
\hline 5 & Talent Mobility Overall & 4.06 & 0.999 \\
\hline 6 & Academic Entrepreneurship & 4.04 & 0.87 \\
\hline 7 & Other Models & 3.73 & 1.164 \\
\hline \multicolumn{2}{|c|}{. } & 4.07 & 0.894 \\
\hline
\end{tabular}

\subsection{Attitudes towards a supporting tool for innovative university assessment system}

The result showed the number and percentage of the opinion from the sample group towards having a supporting tool, such as a mobile web, for innovative university assessment system: Talent Mobility Programme. It was found that most of the samples; 570 people, accounting for 93.0 percent agreed that it was useful, followed by not useful 43 people, representing 7.0 percent as explained in Table 5 .

Table 5. Usefulness of A Supporting Tool for Innovative University Assessment System

\begin{tabular}{|l|c|c|}
\hline \multicolumn{1}{|c|}{ Usefulness of A Supporting Tool (A Mobile Web) } & Number & Percent \\
\hline Useful & 570 & 93 \\
\hline Not Useful & 43 & 7 \\
\hline Overall & 613 & 100 \\
\hline
\end{tabular}


The result showed the number and percentage of the samples' need of a supporting tool, such as a mobile web, for innovative university assessment system: Talent Mobility Programme. It was found that most of the samples; 552 people, accounting for 90.0 percent needed a supporting tool, followed by not needed 61 people, representing 10.0 percent as shown in Table 6 .

Table 6. Need of A Supporting Tool for Innovative University Assessment System

\begin{tabular}{|l|c|c|}
\hline \multicolumn{1}{|c|}{ Need of A Supporting Tool (A Mobile Web) } & Number & Percent \\
\hline Need & 552 & 90 \\
\hline Not Need & 61 & 10 \\
\hline Overall & 613 & 100 \\
\hline
\end{tabular}

In terms of a mobile web's context of use, it will be utilized in a specific setting at the point a system or a product is created. The accomplishment of a software development program can build upon how well this process is completed [16]. User requirements will include summary descriptions of the tasks that the system will support, and functions will be provided to support them.

Our mobile web for Innovative University Assessment System, therefore, should be proved by the technology acceptance theory. The most widely used model in determining user acceptance of new technology usage is Technology Acceptance Model (TAM) [17] [18]. Conducted studies related to mobile technology that utilized numerous theories, including TAM, in understanding the rationale of people in using mobile devices (i.e., smartphones) at work [19].

\section{Developing A Mobile Web for Innovative University Assessment System}

From the data analysis to confirm the theoretical framework of factors influencing academic researchers' decision to participate in the Talent Mobility Programme, and the analysis of models and relationships of factors related to university-industry personnel exchange have led to the product innovation by developing an Innovative University Assessment System for Personnel Sharing to Industry on mobile web for Thailand Talent Mobility Programme of The National Science Technology and Innovation Policy Office (STI).

This product innovation development started from research concepts to innovative product development. Our research results have been developed to be a model of university readiness assessment for personnel sharing, which gives an importance to the commercial use of research community in Thailand. The Innovative University Assessment System for Personnel Sharing to Industry consists of 3 assessment criteria, 4 components, and 48 questions.

The objective of this mobile web is to evaluate the university readiness in various categories as summarized in Table 7 . 
Paper-Developing A Mobile Web for Innovative University Assessment System: Thailand Talent ...

Table 7. Categories and Number of questions in the Innovative University Assessment System

\begin{tabular}{|l|c|}
\hline \multicolumn{1}{|c|}{ Categories } & Number of Questions \\
\hline Organizational Factors and Organization Management & 20 \\
\hline Working Process Factors & 6 \\
\hline Internal Factors & 7 \\
\hline Human Resource Factors & 15 \\
\hline Total & 48 \\
\hline
\end{tabular}

The product called Innovative University Assessment System for Personnel Sharing to Industry is a form of program with a purpose of assessing university readiness in order to support management and administrators to identify strengths, weaknesses, potentials and overall operational effectiveness of the university; which is useful for personnel sharing between universities and industries, specifically for being part of the Thailand Talent Mobility Programme.

\subsection{A mobile web design and usage}

Administrator must generate the right to assess for each university and be the creator of all assessment forms by setting scores for each question and each part in order to support the result calculation as demonstrated in Figure 2 and Figure 3.

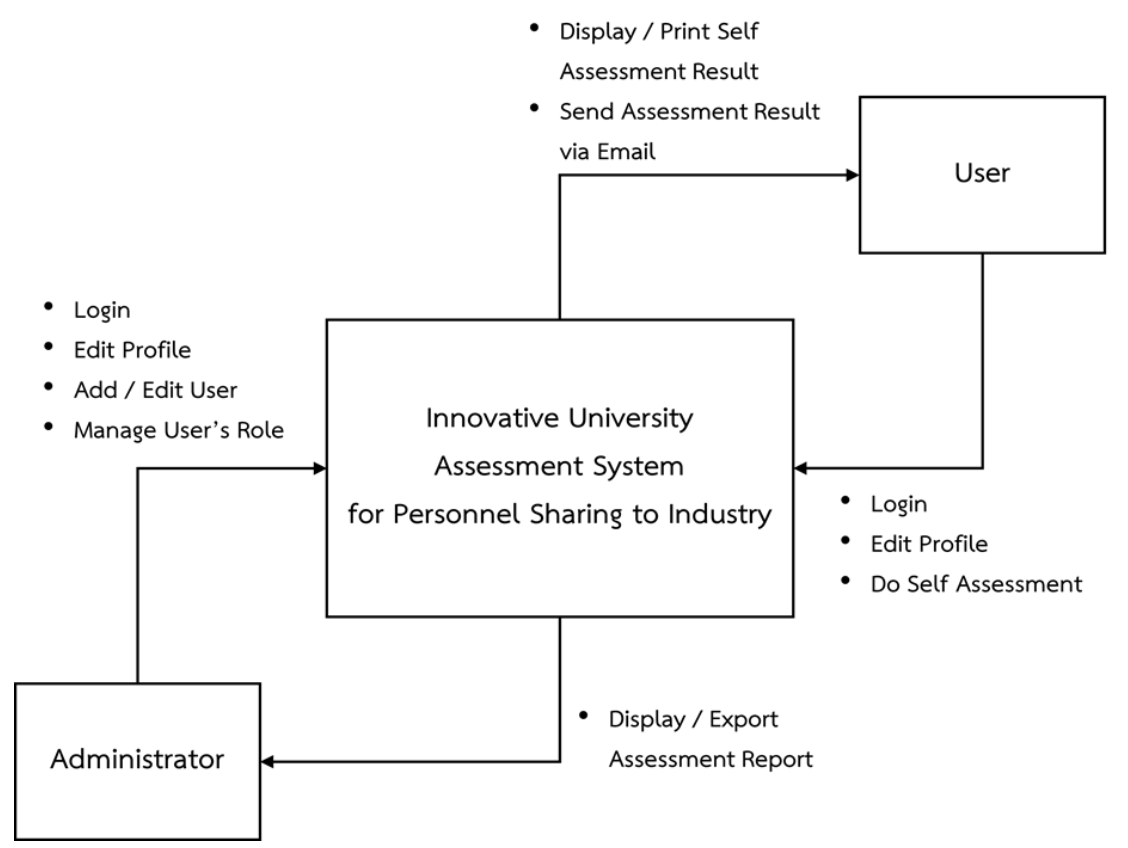

Fig. 2. Context Diagram of A Mobile Web 


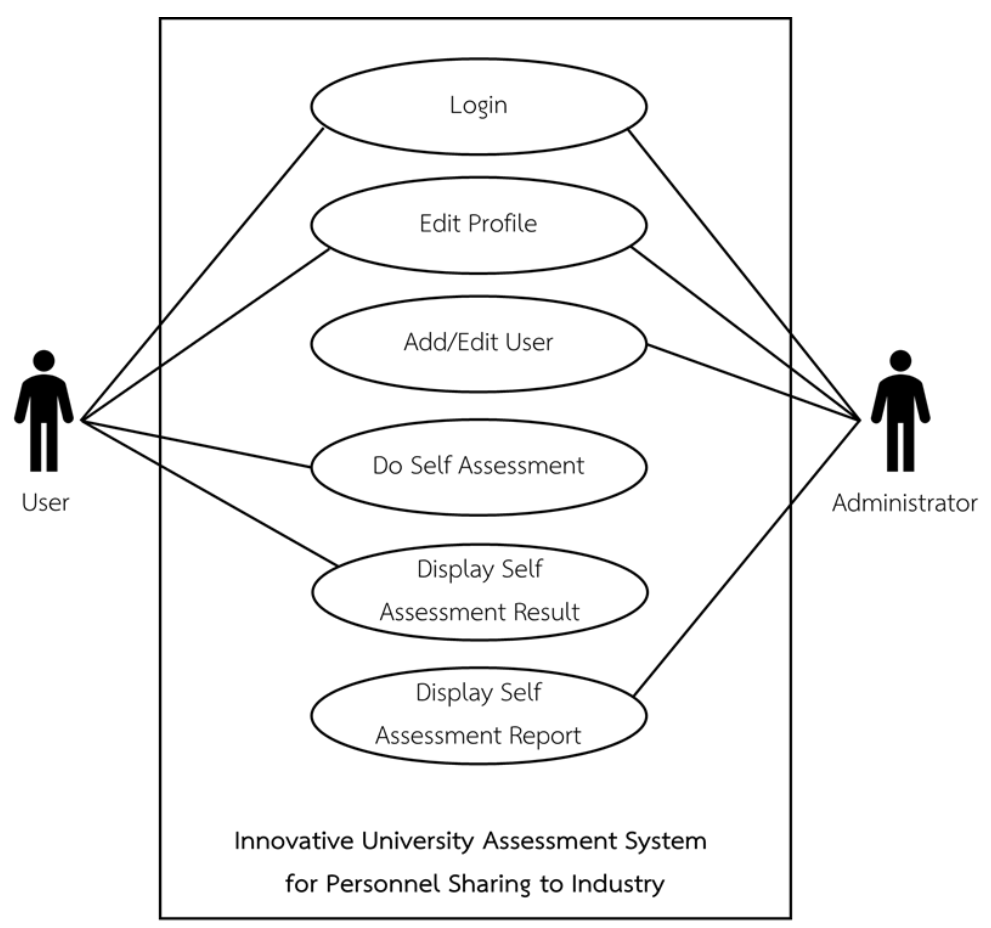

Fig. 3. Use Case Diagram of A Mobile Web

User must have an account for the assessment by applying through the system and be able to understand the result report of each part and the total score summary in order to identify strengths, weaknesses, and potentials of the university as illustrated in Figure 2 and Figure 3.

\subsection{Characteristics and functionality of a mobile web}

Innovative University Assessment System for Personnel Sharing to Industry was developed as a Web Application installed on the Microsoft Azure Cloud Platform system using Microsoft Visual Studio 2017 application with ASP.Net C\#, HTML, and JavaScript under .NET Framework 4.6.1. The data was stored in the relational database with Microsoft SQL Server 2008 R2 as the Database Management System. Reports of the system were designed and developed with Chart.js. Platform Architecture of A Mobile Web as demonstrated in Figure 4. 


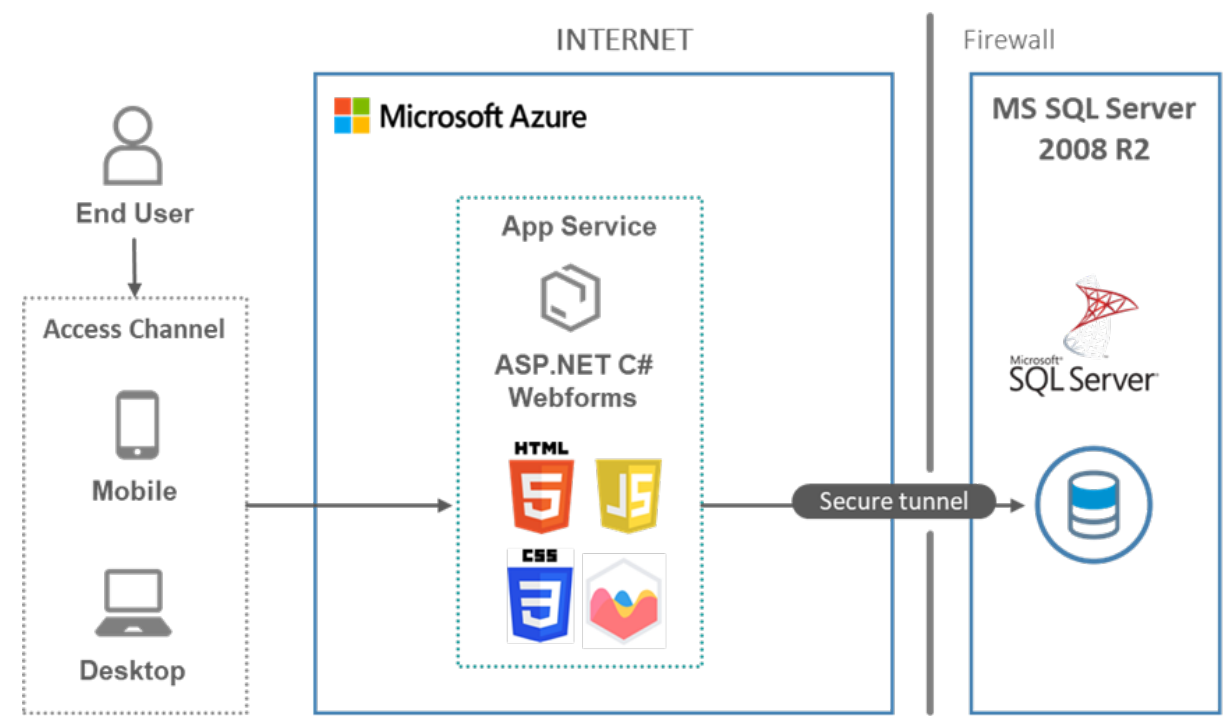

Fig. 4. Platform Architecture of A Mobile Web

Innovative University Assessment System for Personnel Sharing to Industry comprises of two following subsystems as follows:

- User and Security System was developed to manage user's role and permission. User can edit profile and change password of his/her account. Administrator has the right to add new users and edit the information of existing users.

- Assessment System was developed to manage the assessment function. User can do self-assessment for his/her organization. The assessment results are displayed with charts and descriptive information. Administrator can retrieve user's assessment information and export as flat files for further statistical research.

\subsection{Details of a mobile web}

The mobile web consists of three major sections consisting of the University SelfAssessment Form, Assessment Result, and Technology Acceptance of the Innovative University Assessment System as displayed in the following Figure 5, Figure 6, and Figure 7. 
Section 1: University self-assessment form
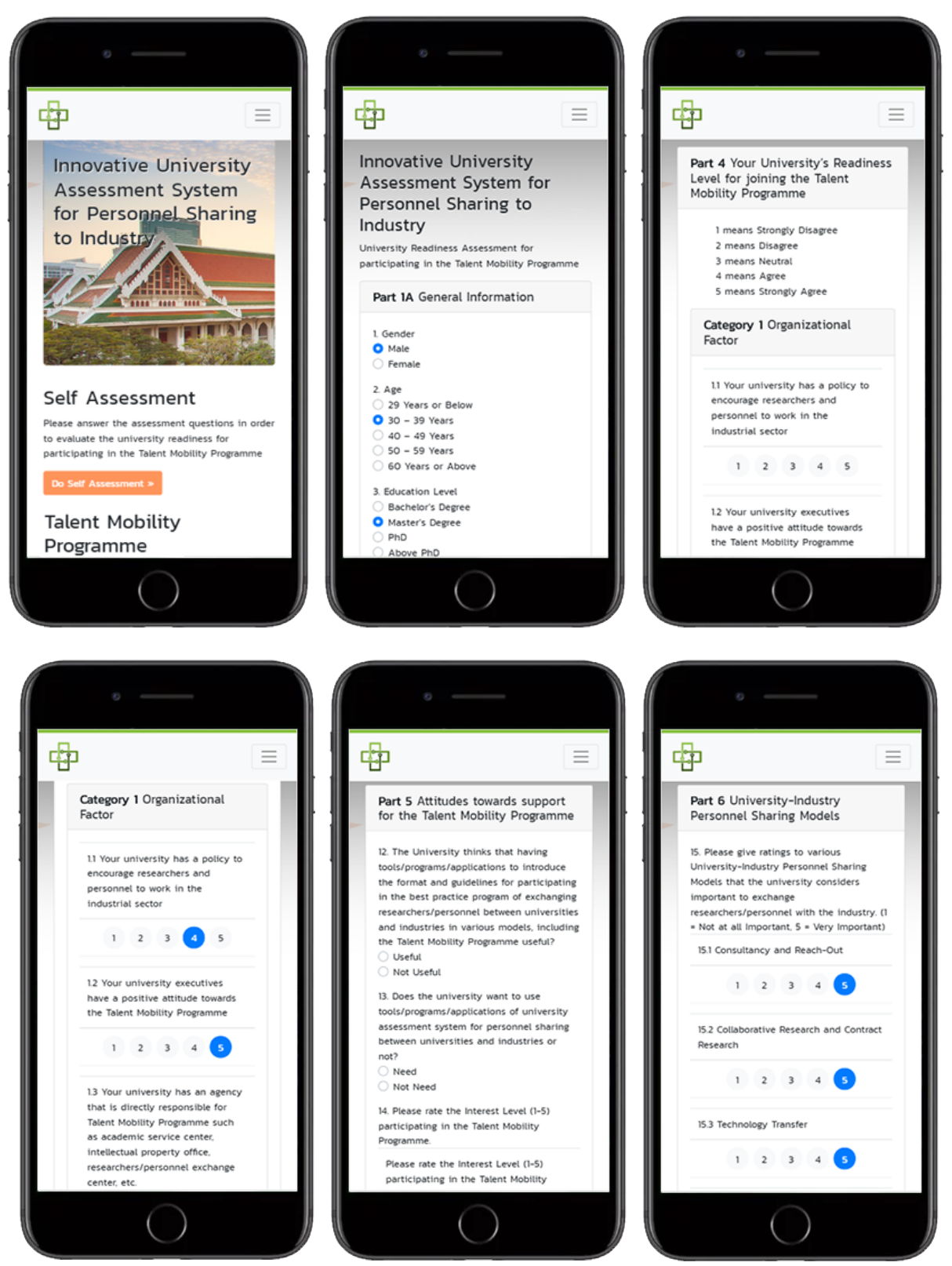

Fig. 5. University Self-Assessment Form 


\section{Section 2: Assessment result}
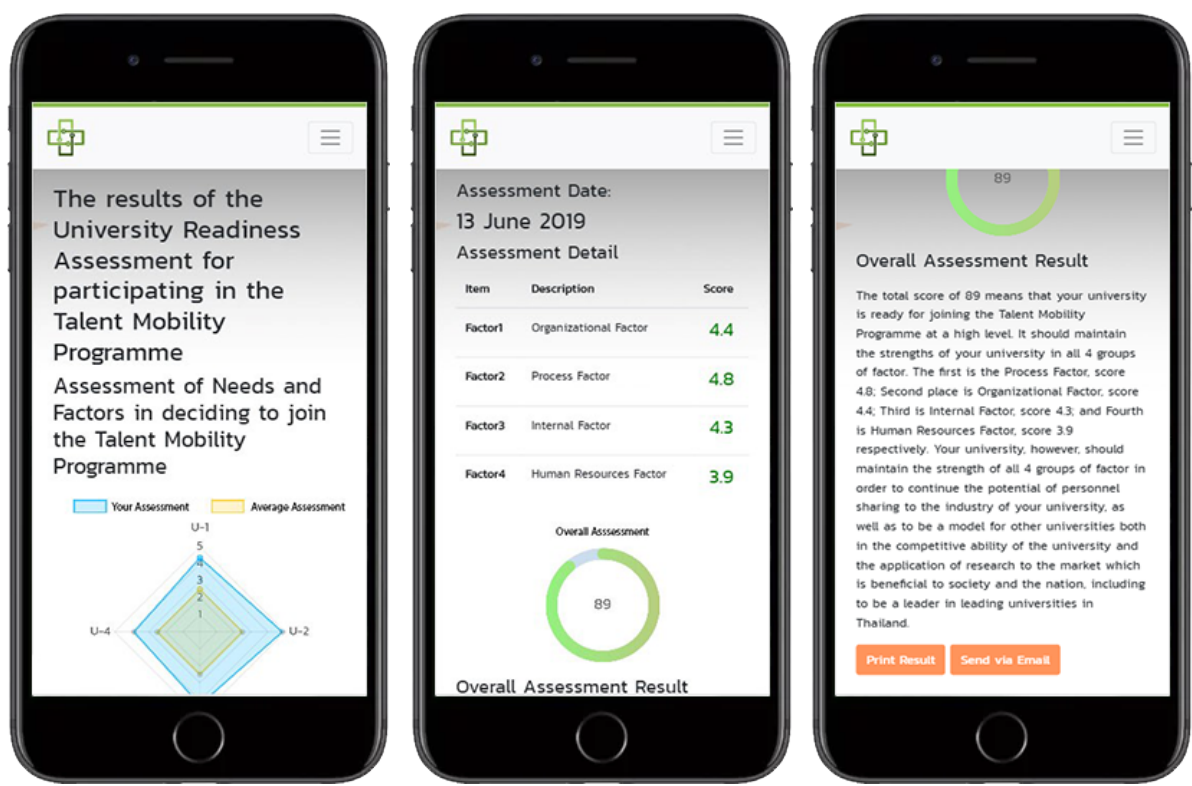

Fig. 6. Assessment Result

Section 3: Technology acceptance of the innovative university assessment system

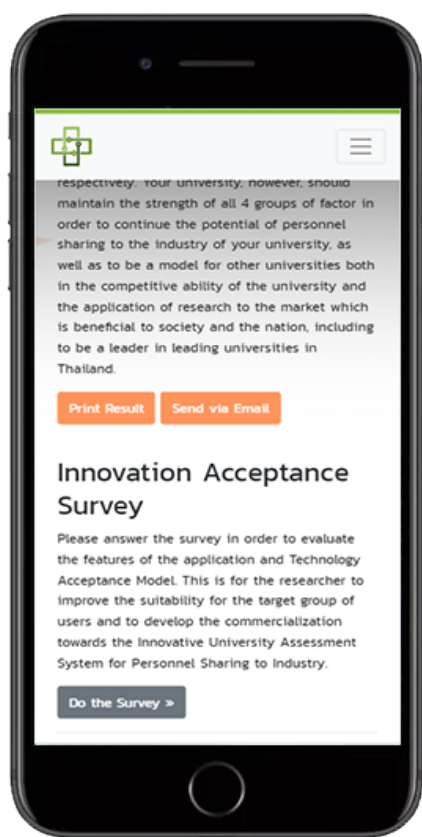

Fig. 7. Technology Acceptance of the Innovative University Assessment System 


\subsection{Usage testing and adoption of a mobile web}

After successfully developing a mobile web called Innovative University Assessment System for Personnel Sharing to Industry, it was brought to have usage and acceptance testing with 30 researchers; responded from 136 academics via direct email distribution, by examining the program usage in order to demonstrate its steps and system as well as the accuracy result calculation of the program. The target group then answered the technology acceptance survey in order to identify the program features to be efficiently improved and suitable for the target group who apply the program.

A survey tool for technology adoption was developed by applying the theory of "Technology Acceptance Model - TAM" [20] which is a popular theory. It was used to describe important factors in technology acceptance and to describe or predict behavior in accepting newly developed information systems [21]. TAM is shown in Figure 8 .

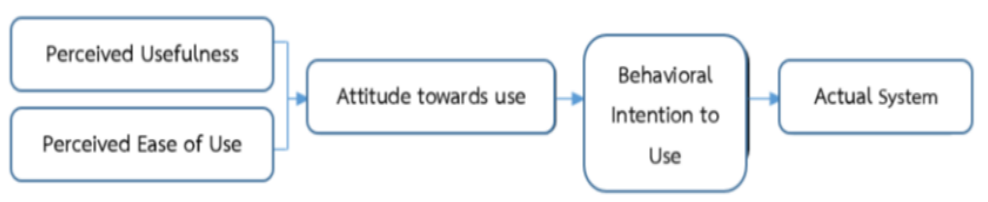

Fig. 8. Technology Acceptance Model - TAM

Technology Acceptance Model (TAM) is a theory describing user's perception of benefits from information technology. There are factors determining the perception of each person that information technology contributes to improving efficiency and factors directly affecting the intention to use. Technology Acceptance Model consists of Perceived Usefulness, Perceived Ease of Use, Attitude towards Use, and Behavioral Intention to Use.

Perceived Usefulness is a factor that determines the perception of benefits from information technology. Perceived Ease of Use is a factor determining the amount or success that meet the needs or expectations which is a factor that affects the perception of the benefits derived from information technology [20]. Attitude towards Use is influenced by perception of benefits from information technology and recognition that the system is easy to use. Behavioral Intention to Use is influenced by the attitude towards use and awareness of the benefits derived from information technology which ultimately resulting in the acceptance of actual use.

\section{Conclusions and Recommendations}

University-industry linkage is increasingly playing a significant role in developing innovation supply chains and knowledge transfer ecosystems [8]. It is critical to understand the nature of university-industry partnership, its effectiveness and potential 
barriers to ensure effective knowledge transfer, competitiveness and developing knowledge-based economies [22].

Industry factors play a key role in affecting academic researchers' participation decision on the Talent Mobility Programme. These included internal factors, and organizational factors and organization management of the industry. University factors also have an overall significant influence on mentioned experts' decision making. They were the university's internal factors and working process of the university.

As this study has presented the critical factors that influence the participation decision on the Talent Mobility Programme, and this knowledge is crucial in managing such collaboration model. This effort, therefore, will also help to observe the significant personnel sharing models between university and industry.

As our findings highlighted key factors and significant models, this study was finally designed to determine the acquisition of academic researchers towards a mobile web for Innovative University Assessment System. The proposed framework can be successfully utilized as a decision-making tool for university assessment of its characteristics, and potential research collaboration models with industry will be recommended. Results indicated that academic researchers were optimistic regarding its value and expressed their intention to adopt this tool called Innovative University Assessment System for Personnel Sharing to Industry.

This research study, however, only discussed on factors effecting participation decision on Thailand Talent Mobility Programme from the perspectives of academic researchers in Science, Technology, and Innovation. Future research, therefore, should explore in other models of personnel sharing and from the perspectives of industry in order to compare university-industry collaborations that would reveal different results. Other supporting tools such as mobile application, moreover, to assess industry readiness for personnel sharing should be further developed and introduced.

\section{$7 \quad$ References}

[1] E. Geisler, A. Furino, and T. J. Kiresuk, "Factors in the success or failure of industryuniversity cooperative research centers," Interfaces, vol. 20, no. 6, pp. 99-109, 1990. https: //doi.org/10.1287/inte.20.6.99

[2] H. Prabowo, T. W. Cenggoro, A. Budiarto, A. S. Perbangsa, H. H. Muljo, and B. Pardamean, "Utilizing Mobile-based Deep Learning Model for Managing Video in Knowledge Management System," International Journal of Interactive Mobile Technologies (iJIM), vol. 12, no. 6, pp. 62-73, 2018. [Online]. https://doi.org/10.3991/ijim.v12i6.8563.

[3] A. M. B. Barbolla and J. R. C. Corredera, "Critical factors for success in universityindustry research projects," Technology Analysis \& Strategic Management, vol. 21, no. 5, pp. 599-616, 2009. https://doi.org/10.1080/09537320902969133

[4] C. N. Madu, "Transferring technology to developing countries - Critical factors for success," Long Range Planning, vol. 22, no. 4, pp. 115-124, 1989. https://doi.org/10.1016/00 24-6301(89)90089-7

[5] R. Svensson, "Knowledge transfer to emerging markets via consulting projects," The Journal of Technology Transfer, vol. 32, no. 5, pp. 545-559, 2007. https://doi.org/10.1007/s10 961-007-9034-2 
[6] T. Williamsz, "New technology, human resources and competitiveness in developing countries: the role of technology transfer," The International Journal of Human Resource Management, vol. 7, no. 4, pp. 832-845, 1996. https://doi.org/10.1080/0958519960000015 $\underline{8}$

[7] U. Kumar, V. Kumar, S. Dutta, and K. Fantazy, "State sponsored large scale technology transfer projects in a developing country context," The Journal of Technology Transfer, vol. 32, no. 6, pp. 629-644, 2007. https://doi.org/10.1007/s10961-006-8880-7

[8] T. Schofield, "Critical Success Factors for Knowledge Transfer Collaborations between University and Industry," Journal of Research Administration, vol. 44, no. 2, pp. 38-56, 2013.

[9] F. Rossi and A. Rosli, "Indicators of university-industry knowledge transfer performance and their implications for universities: evidence from the United Kingdom," Studies in Higher Education, vol. 40, no. 10, pp. 1970-1991, 2015. https://doi.org/10.1080/03075079. $\underline{2014.914914}$

[10] H. Etzkowitz and L. Leydesdorff, "The dynamics of innovation: from National Systems and "Mode 2" to a Triple Helix of university-industry-government relations," Research policy, vol. 29, no. 2, pp. 109-123, 2000. https://doi.org/10.1016/s0048-7333(99)00055-4

[11] A. Inzelt, "The evolution of university-industry-government relationships during transition," Research policy, vol. 33, no. 6-7, pp. 975-995, 2004. https://doi.org/10.1016/j.respol. 2004.03.002

[12] K. Kongsoontornkijkul, R. Pichyangkura, P. Vadhanasindhu, and K. Vanichbuncha, "A study of factors effecting Thailand talent mobility programme: Case of university and food technology industry," in 2017 12th International Conference for Internet Technology and Secured Transactions (ICITST), 2017: IEEE, pp. 444-449. https://doi.org/10.23919/icitst.2 $\underline{017.8356443}$

[13] N. Siripitakchai and K. Miyazaki, "University-Industry Linkages (UILs) and Research Collaborations: Case of Thailand's National Research Universities (NRUs)," in Industrial Engineering, Management Science and Applications 2015: Springer, 2015, pp. 189-198. https://doi.org/10.1007/978-3-662-47200-2 22

[14] A. Kitipongwatana, K. Kaweekijmanee, O. Wiarachai, and P. Koseeyaporn, "An Empirical Study of PolicyImplementation of Thailand Talent Mobility Programme," in 2016. Presented at the 13th International Conference ASIALICS, 2016. https://doi.org/10.14203/stip $\underline{\mathrm{m} .2017 .112}$

[15] K. Kaymaz and K. Y. Eryiğit, "Determining factors hindering university-industry collaboration: An analysis from the perspective of academicians in the context of entrepreneurial science paradigm," International Journal of Social Inquiry, vol. 4, no. 1, 2011.

[16] R. Dermawi, H. Tolle, and I. Aknuranda, "Design and Usability Evaluation of Communication Board for Deaf People with User-Centered Design Approach," International Journal of Interactive Mobile Technologies (iJIM), vol. 12, no. 2, pp. 197-206, 2018. https://doi. org/10.3991/ijim.v12i2.8100.

[17] J. Ho Cheong and M.-C. Park, "Mobile internet acceptance in Korea," Internet research, vol. 15, no. 2, pp. 125-140, 2005. https://doi.org/10.1108/10662240510590324

[18] E. Mao, M. Srite, J. Bennett Thatcher, and O. Yaprak, "A research model for mobile phone service behaviors: empirical validation in the US and Turkey," Journal of Global Information Technology Management, vol. 8, no. 4, pp. 7-28, 2005. https://doi.org/10.1080/10 97198x.2005.10856406

[19] B. M. Al-Mahadeen, "Factors Affecting the Readiness of Medical Doctors and Patients with Chronic Conditions toward the Usage of Smartphones in the Saudi Arabian 
Healthcare Sector," International Journal of Interactive Mobile Technologies, vol. 9, no. 1, 2015. https://doi.org/10.3991/ijim.v9i1.4279.

[20] F. D. Davis, R. P. Bagozzi, and P. R. Warshaw, "User acceptance of computer technology: a comparison of two theoretical models," Management science, vol. 35, no. 8, pp. 9821003, 1989. https://doi.org/10.1287/mnsc.35.8.982

[21] P. Surendran, "Technology acceptance model: A survey of literature," International Journal of Business and Social Research, vol. 2, no. 4, pp. 175-178, 2012.

[22] A. S. V. Yee, A. L. Chong, and G. Kendall, "Managing University-Industry Collaborations in Malaysia by Examining its Critical Success Factors: A Dyadic Approach," World Review of Business Research, vol. 5, no. 3, pp. 213-230, 2015.

\section{$8 \quad$ Funding}

The research is funded by the grant of THE $90^{\mathrm{TH}}$ ANNIVERSARY OF CHULALONGKORN UNIVERSITY FUND (Ratchadaphiseksomphot Endowment Fund)

\section{Acknowledgements}

Prof. Emeritus Achara Chandrachai, Ph.D., the Professor Emeritus of Technopreneurship and Innovation Management Program, Graduate School, Chulalongkorn University; who gave valuable advice and great recommendations on interview topics and questionnaire survey for this research study.

Narissara Muangsawang, Ph.D. National Research Council of Thailand.

Wuttikorn Ngokkownok. National Research Council of Thailand.

\section{Authors}

Kritika Kongsoontornkijkul is a Doctor of Philosophy candidate at Technopreneurship and Innovation Management Program, Graduate School, Chulalongkorn University, Bangkok, Thailand. (E-mail: kkritika@hotmail.com)

Rath Pichyangkura is Assistant Professor at the Department of Biochemistry, Faculty of Science, Chulalongkorn University, Bangkok, Thailand.

Pakpachong Vadhanasindhu is Associate Professor at Technopreneurship and Innovation Management Program, Graduate School, Chulalongkorn University, Bangkok, Thailand.

Kanlaya Vanichbuncha is Associate Professor at the Department of Statistics, Faculty of Commerce and Accountancy, Chulalongkorn University, Bangkok, Thailand.

Article submitted 2019-05-26. Resubmitted 2019-07-06. Final acceptance 2019-07-10. Final version published as submitted by the authors. 